\title{
NOVEL THERMODYNAMIC PROPERTIES OF BINARY MIXTURES OF TETRAHYDROFURFURYL ALCOHOL WITH SOME ALCOHOLS AT 298.15 K
}

\author{
S. A. Salman ${ }^{1}$, S. A. Al-Khfaji ${ }^{1}$, K. I. Hussain ${ }^{1}$, Z.A.Al-Dulaimy ${ }^{1}$, \\ A. M. Abbas ${ }^{1}$ and D.T. A. Al-Heetimi ${ }^{1, *}$ \\ ${ }^{1}$ Department of Chemistry, College of Education for Pure Science Ibn-Al-Haitham, University of \\ Baghdad, Baghdad, Iraq \\ *E-mail: dhafir1973@gmail.com
}

\begin{abstract}
To understand the nature of molecular aggregation between two solvents, excess properties (e.g. excess molar volume $\left(V_{\mathrm{m}}^{\mathrm{E}}\right)$, excess Gibb's free energy of activation viscous flow $\left(\Delta \mathrm{G}^{* \mathrm{E}}\right)$ and viscosity deviation of binary mixtures) are therefore needed. Thus, in the current study, the refractive index $\left(n_{D}\right)$, viscosity $(\eta)$, and density $(\rho)$ of binary mixtures were measured for tetrahydrofurfuryl alcohol (THFA) with ethanol, 2-propanol and 2-butanol at 298.15K. Moreover and based on experimentally obtained results, the $V_{m}^{E}$, the refractive index deviation $\left(\Delta n_{D}\right)$, excess molar viscosity $\left(\eta^{\mathrm{E}}\right)$ and $\Delta \mathrm{G}^{* \mathrm{E}}$ were calculated. To correct and fit the experimental $\mathrm{V}_{\mathrm{m}}^{\mathrm{E}}, \eta^{\mathrm{E}}$ and $\Delta \mathrm{n}_{\mathrm{D}}$ deviations, Redlich-Kister equation was used. The molecular interaction in binary mixtures was found to explain the variability of physical properties with the composition of the mixtures. In light of obtained results, factors influencing the molecular interactions (e.g. the length of the carbon chain and the position of hydroxyl groups in targeted alcohol) have been also discussed. In all cases the obtained $V_{m}^{E}, \eta^{E}, \Delta G^{* E}$ and $\Delta n_{D}$ values were negative at $298.15 \mathrm{~K}$ except for the binary system (THFA +2 butanol) where the results indicate the positive deviation in refractive indices.

Keywords: Binary system, tetrahydrofurfuryl alcohol, refractive index, density, viscosity, thermodynamic properties.
\end{abstract}

(c) RASĀYAN. All rights reserved

\section{INTRODUCTION}

In binary liquid solvents mixtures, the excess thermodynamic functions are the key tool for understanding the molecular interactions behavior, they were highly used in the chemical engineering industry for chemical reaction cleaning, extraction and purification ${ }^{1}$. Additionally, physical properties of binary mixtures are essential when heat transfer and mass transfer phenomena involved in industrial processes ${ }^{2}$.

A considerable amount of research studying the properties of binary solvent mixtures has been published in the recent decade ${ }^{3-8}$. Hydrogen bond formation, dipole-dipole, and charge transfer interactions have been suggested as the mechanisms of interactions between of solvents ${ }^{9-11}$. For example, $\mathrm{Nain}^{3}$ studied the densities and volumetric properties of binary mixtures of formamide with alcohols at two temperatures and found that negative $V_{m}^{E}$ is attributed to the formation of hydrogen bond interaction. This was confirmed by Kemeakegha ${ }^{12}$ when studied the behavior of binary mixtures of organic solvents and amines. Moreover, $\rho$, $\eta$ and $n_{D}$ measurement is expected to shed some light on both solvent-solute interactions ${ }^{13}$. On the other hand, and up to our knowledge, no study was done to investigate the $\mathrm{V}^{\mathrm{E}}, \eta^{\mathrm{E}}, \Delta \mathrm{n}_{\mathrm{D}}$ and $\Delta \mathrm{G}^{* \mathrm{E}}$ at any temperature. Therefore, the objective of this research is to study excess properties including $\rho, \eta$ and $n_{D}$ for a range of binary mixtures including (THFA+ Ethanol), (THFA+ 2-propanol) and (THFA + 2-butanol) at $298.15 K$. From obtained results, another parameter such as $\mathrm{V}_{\mathrm{m}}^{\mathrm{E}}$, viscosity deviation, refractive index deviation and Gibbs free energy (excess molar) were also determined.

\section{Chemicals}

\section{EXPERIMENTAL}

All solvents used in the study are of high purity (>99\%) Tetrahydrofurfuryl alcohol (THFA), 2-propanol, 2-butanol , and ethanol were purchased from Sigma-Aldrich (UK). The purities of this experiment used 
solvents were checked and results showed high compatibility to those in previous studies (Table-1). Densities, viscosities, and refractive indices were listed for all solvents except THFA where no data available in the literature.

\section{Density and Viscosity Measurements}

The average $\rho$ value of three replicates was determined with a precision of $\pm 10^{-5} \mathrm{~g} . \mathrm{cm}^{-3}$ using a digital density meter (Anton paar, Model DMA 60/602). For viscosity $(\eta)$ measurements, a controlled temperature suspended-level ubbelohde viscometer was used under atmospheric pressure at $298.15 \pm 0.01 \mathrm{~K}$. The final values represent the average of three measurements.

\section{Refractive Index Measurements}

A digital Abbe refractometer (Model:BOE 32400) was used to measure the $n_{D}$ values for both pure and their binary mixtures solvents. Pure toluene and double distilled water were used for refractometer calibration, at a temperature of $298.15 \mathrm{~K}$.

Table-1: This study and literature obtained density $(\rho)$, viscosity $(\eta)$ and refractive index $\left(\mathrm{n}_{\mathrm{D}}\right)$ values for solvents at

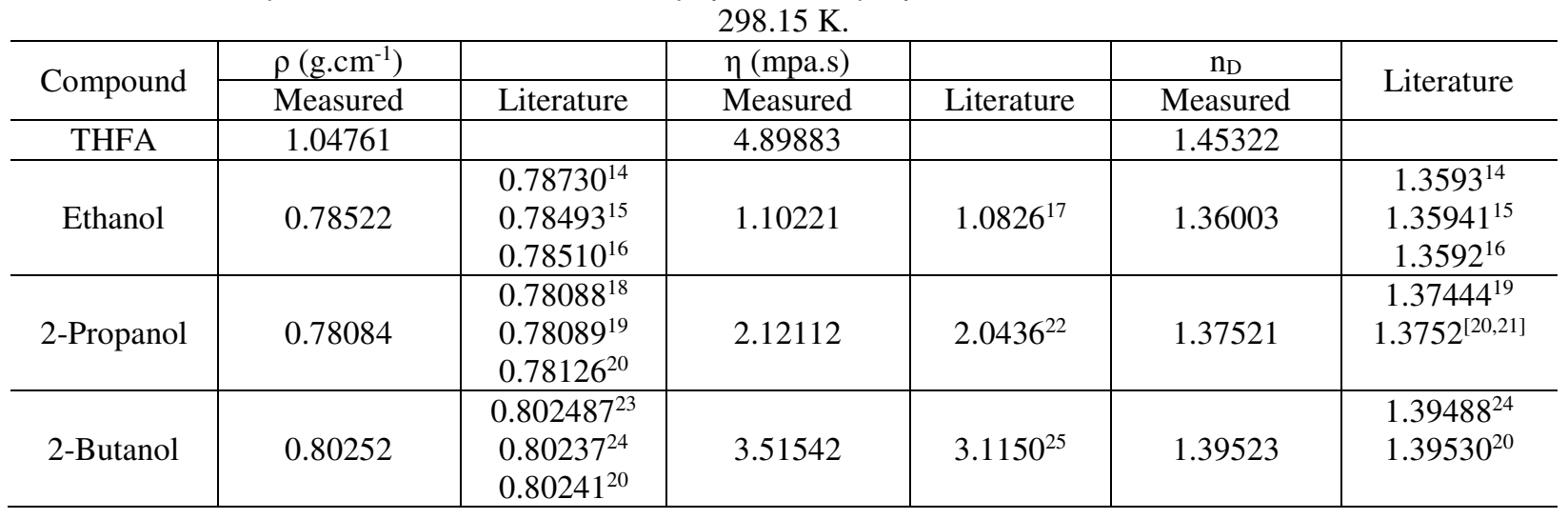

\section{RESULTS AND DISCUSSION}

In the current study, measured density $(\rho)$ values were used to estimate the $V_{\mathrm{m}}^{\mathrm{E}}$ of the binary mixtures following the equation $(1)^{26}$ :

$V_{m}^{E}=\frac{X_{1} M_{1}+X_{2} M_{2}}{\rho_{m}}-\frac{X_{1} M_{1}}{\rho_{1}}-\frac{X_{2} M_{2}}{\rho_{2}}$

Where $M_{1}, X_{1}$, and $\rho_{1}$ are the molecular weight $\left(M_{w t}\right)$, mole fraction, and density of the pure THFA, respectively; while $M_{2}, X_{2}$ and $\rho_{2}$ are the $M_{w t}$, mole fraction and density of alcohols, $\rho_{\mathrm{m}}$ is the density of the binary mixtures, respectively.Table -2 lists the density and $\mathrm{V}_{\mathrm{m}}^{\mathrm{E}}$ of the binary mixtures at the various mole fractions of THFA and (ethanol, 2-propanol and 2-butanol). The $\mathrm{V}_{\mathrm{m}}^{\mathrm{E}}$ plotted against $\left(\mathrm{X}_{1}\right)$ mole fraction for THFA is shown in Fig. -1.

Table-2: Experimentally obtained density, viscosity and refractive index values and their corresponding parameters values in binary solvents Mixtures.

\begin{tabular}{c|c|c|c|c|c|c|c}
\hline \multicolumn{7}{c}{$\mathrm{X}_{1}$ THFA $+\mathrm{X}_{2}$ Ethanol at $298.15 \mathrm{~K}$} \\
\hline $\mathrm{X}_{1}$ & $\rho\left(\mathrm{g} \mathrm{cm}^{3}\right)$ & $\mathrm{V}^{\mathrm{E}} \mathrm{cm}^{3} \mathrm{~mol}^{-1}$ & $\mathrm{n}_{\mathrm{D}}$ & $\Delta \mathrm{n}_{\mathrm{D}}$ & $\eta$ & $\eta^{\mathrm{E}} \mathrm{mpa} . \mathrm{s}$ & $\begin{array}{c}\Delta \mathrm{G}^{* \mathrm{E}} \\
\mathrm{J} \mathrm{mol}^{-1}\end{array}$ \\
\hline 0.0000 & 0.78522 & 0.0000 & 1.36003 & 0.0000 & 1.10221 & 0.0000 & 0.0000 \\
\hline 0.0556 & 0.81012 & -0.11407 & 1.36505 & -0.55088 & 1.10534 & -0.08011 & -178.99553 \\
\hline 0.2003 & 0.86480 & -0.18979 & 1.37553 & -1.66105 & 1.31196 & -0.12458 & -252.46773 \\
\hline
\end{tabular}


RASĀYAN J. Chem.

Vol. 11 | No. 2 |589 - 596 | April - June | 2018

\begin{tabular}{c|c|c|c|c|c|c|c}
\hline 0.2717 & 0.88824 & -0.20756 & 1.38417 & -1.89185 & 1.43335 & -0.14260 & -285.66860 \\
\hline 0.4115 & 0.92906 & -0.22680 & 1.39508 & -2.25869 & 1.72669 & -0.16493 & -329.93131 \\
\hline 0.5054 & 0.95301 & -0.21833 & 1.40398 & -2.24400 & 1.99616 & -0.16551 & -351.24693 \\
\hline 0.6219 & 0.97940 & -0.17580 & 1.41302 & -2.11791 & 2.41119 & -0.14481 & -287.69246 \\
\hline 0.7334 & 1.00195 & -0.12520 & 1.42197 & -1.81120 & 2.93841 & -0.11345 & -223.83736 \\
\hline 0.8055 & 1.01378 & -0.09323 & 1.42880 & -1.48260 & 3.33886 & -0.09324 & -186.08495 \\
\hline 0.9278 & 1.036461 & -0.05379 & 1.43914 & -0.84900 & 4.16206 & -0.05529 & -118.46276 \\
\hline 1.0000 & 1.04761 & 0.0000 & 1.45322 & 0.0000 & 4.89883 & 0.0000 & 0.0000 \\
\hline
\end{tabular}

\begin{tabular}{c|c|c|c|c|c|c|c}
\hline \multicolumn{7}{c}{$\mathrm{X}_{1} \mathrm{THFA}+\mathrm{X}_{2} 2-$ propanol at 298.15 } \\
\hline $\mathrm{X}_{1}$ & $\rho\left(\mathrm{g} . \mathrm{cm}^{-3}\right)$ & $\mathrm{V}^{\mathrm{E}} \mathrm{cm}^{3} \mathrm{~mol}^{-1}$ & $\mathrm{n}_{\mathrm{D}}$ & $\Delta \mathrm{n}_{\mathrm{D}}$ & $\eta$ & $\eta^{\mathrm{E}} \mathrm{mpa} . \mathrm{s}$ & $\begin{array}{c}\Delta \mathrm{G}^{* \mathrm{E}} \\
\mathrm{J} . \mathrm{mol}^{-1}\end{array}$ \\
\hline 0.0000 & 0.78084 & 0.0000 & 1.37521 & 0.0000 & 2.12112 & 0.0000 & 0.0000 \\
\hline 0.1101 & 0.82262 & -0.54309 & 1.38772 & -0.12789 & 2.18949 & -0.06044 & -142.59655 \\
\hline 0.2240 & 0.86442 & -1.14715 & 1.40052 & -0.17011 & 2.35137 & -0.08445 & -196.76866 \\
\hline 0.3408 & 0.90885 & -2.07105 & 1.41189 & -0.19689 & 2.54123 & -0.10456 & -243.27626 \\
\hline 0.4539 & 0.94311 & -2.32896 & 1.42105 & -0.22405 & 2.74769 & -0.12113 & -282.99355 \\
\hline 0.5534 & 0.96779 & -2.19084 & 1.42811 & -0.23356 & 2.96293 & -0.12899 & -302.81608 \\
\hline 0.6497 & 0.98765 & -1.80049 & 1.43439 & -0.21909 & 3.24407 & -0.11895 & -279.48010 \\
\hline 0.7472 & 1.00770 & -1.49545 & 1.43999 & -0.19451 & 3.59524 & -0.09778 & -229.82004 \\
\hline 0.8353 & 1.02229 & -0.97714 & 1.44435 & -0.16946 & 3.96494 & -0.07448 & -173.51734 \\
\hline 0.9249 & 1.03612 & -0.42426 & 1.44555 & -0.11083 & 4.36632 & -0.05221 & -124.93248 \\
\hline 1.0000 & 1.04761 & 0.0000 & 1.45322 & 0.0000 & 4.89883 & 0.0000 & 0.0000 \\
\hline \multicolumn{7}{c}{$\mathrm{X}_{1} \mathrm{THFA}+\mathrm{X}_{2} 2-$ butanol at $298.15 \mathrm{~K}$} \\
\hline
\end{tabular}

\begin{tabular}{c|c|c|c|c|c|c|c}
\hline $\mathrm{X}_{1}$ & $\rho\left(\mathrm{g} . \mathrm{cm}^{-3}\right)$ & $\mathrm{V}^{\mathrm{E}} \mathrm{cm}^{3} \mathrm{~mol}^{-1}$ & $\mathrm{n}_{\mathrm{D}}$ & $\Delta \mathrm{n}_{\mathrm{D}}$ & $\eta$ & $\eta^{\mathrm{E}} \mathrm{mpa} . \mathrm{s}$ & $\Delta \mathrm{G}^{\mathrm{EE}}{\mathrm{J} . \mathrm{mol}^{-1}}^{-1.39523}$ \\
\hline 0.0000 & 0.80252 & 0.0000 & 0.0000 & 3.51542 & 0.0000 & 0.0000 \\
\hline 0.0940 & 0.83401 & -0.81245 & 1.40329 & 0.10142 & 3.52793 & -0.02765 & -68.213775 \\
\hline 0.2027 & 0.86405 & -1.04580 & 1.41112 & 0.21055 & 3.57309 & -0.05099 & -115.61921 \\
\hline 0.2978 & 0.88871 & -1.09891 & 1.42019 & 0.31392 & 3.60972 & -0.07235 & -178.57860 \\
\hline 0.4044 & 0.91574 & -1.12394 & 1.42833 & 0.40165 & 0.68238 & -0.08779 & -216.76150 \\
\hline 0.4993 & 0.93852 & -1.04328 & 1.43429 & 0.42228 & 3.79225 & -0.0889 & -221.91290 \\
\hline 0.5946 & 0.96038 & -0.88946 & 1.43745 & 0.36444 & 3.94820 & -0.08121 & -200.4288 \\
\hline 0.6958 & 0.98330 & -0.72903 & 1.44266 & 0.28581 & 4.15021 & -0.06489 & -160.08807 \\
\hline 0.8040 & 1.00733 & -0.54637 & 1.44738 & 0.22631 & 4.39545 & -0.04338 & -101.70914 \\
\hline 0.9059 & 1.02899 & -0.31478 & 1.45081 & 0.12573 & 4.64281 & -0.02245 & -55.34835 \\
\hline 1.0000 & 1.04761 & 0.0000 & 1.45322 & 0.0000 & 4.89883 & 0.0000 & 0.0000 \\
\hline
\end{tabular}

Excess molar volume $\left(\mathrm{V}^{\mathrm{E}}\right)$, refractive index deviation $\left(\Delta \mathrm{n}_{\mathrm{D}}\right)$, excess molar viscosities $\left(\eta^{\mathrm{E}}\right)$ and excess molar Gibbs free energy $\left(\Delta \mathrm{G}^{* \mathrm{E}}\right)$. 


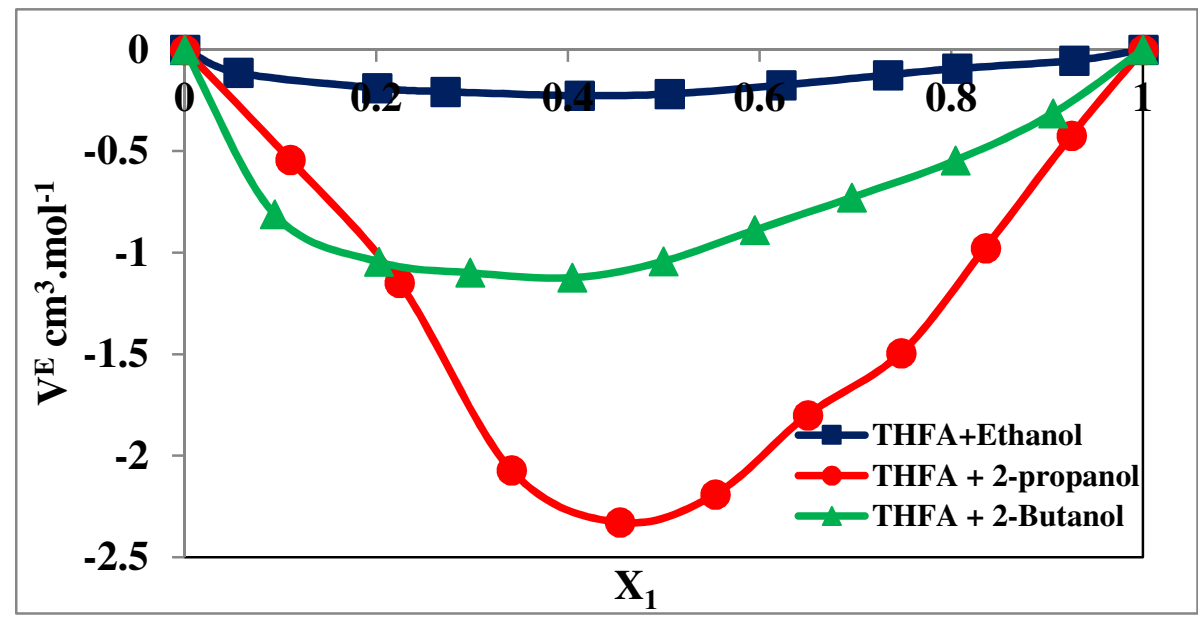

Fig.-1: Plots $\left(\mathrm{V}^{\mathrm{E}}\right)$ excess molar volume against $\mathrm{X}_{1}$ for $\left(\mathrm{X}_{1} \mathrm{THFA}+\mathrm{X}_{2}\right.$-Mono alcohols) at $298.15 \mathrm{~K}$.

\section{Refractive index deviation}

Refractive index deviation $\left(\Delta \mathrm{n}_{\mathrm{D})}\right.$ was calculated using equation $(2)^{27}$ :

$\Delta \mathrm{n}_{\mathrm{D}}=\mathrm{n}_{\mathrm{D}}-\mathrm{X}_{1} \mathrm{n}_{\mathrm{D} 1}-\mathrm{X}_{2} \mathrm{n}_{\mathrm{D} 2}$

Where $\mathrm{n}_{\mathrm{D}}$ is the refractive index of the mixture and $\left(\mathrm{n}_{\mathrm{D} 1}, \mathrm{n}_{\mathrm{D} 2}\right)$ are pure component refractive index.

Lorentz-Lorenz equation $(3,4$, and 5$){ }^{28}$ were used to calculate $\left(\mathrm{n}_{\mathrm{D} 1}, \mathrm{n}_{\mathrm{D} 2}\right.$ and $\mathrm{n}_{\mathrm{D})}$ as follows:

$\mathrm{n}_{\mathrm{D}}=\left(\frac{n_{m}^{2}-1}{\mathrm{n}_{m}^{2}+2}\right) \frac{\mathrm{X} 1 \mathrm{M} 1+\mathrm{X} 2 \mathrm{M} 2}{\rho_{\mathrm{m}}}$

$\mathrm{n}_{\mathrm{D} 1}=\left(\frac{\mathrm{n}_{1}^{2}-1}{\mathrm{n}_{1}^{2}+2}\right) \frac{\mathrm{X} 1 \mathrm{M} 1}{\rho_{1}}$

$\mathrm{n}_{\mathrm{D} 2}=\left(\frac{\mathrm{n}_{2}^{2}-1}{\mathrm{n}_{2}^{2}+2}\right) \frac{\mathrm{X} 2 \mathrm{M} 2}{\rho_{2}}$

Table -2 lists the experimental $\left(\mathrm{n}_{\mathrm{D}}\right.$, and $\Delta \mathrm{n}_{\mathrm{D}}$ ) values of the binary mixtures, while Fig-2 illustrates the relation between $\Delta \mathrm{n}_{\mathrm{D}}$ against mole fraction $\left(\mathrm{X}_{1}\right)$ for the THFA .

\section{Excess molar viscosities $\left(\eta^{\mathbf{E}}\right)$}

Excess molar viscosities $\left(\eta^{\mathrm{E}}\right)$ were obtained by using equation $(6)^{29}$ :

$\left(\eta^{\mathrm{E}}\right)=\left(\eta_{\mathrm{m}}\right)-\left(\mathrm{X}_{1} \eta_{1}+\mathrm{X}_{2} \eta_{2}\right)$

Where $X_{1}, X_{2}, \eta 1, \eta 2$ are the mole fraction and the viscosity of the components 1 and 2 ; while $\eta_{\mathrm{m}}$ is the viscosity of the mixture, as listed in Table -2 . The relation between the $\eta^{\mathrm{E}}$ against mole fraction $\left(\mathrm{X}_{1}\right)$ for THFA is shown in Fig-3.

\section{Excess molar Gibbs free energy}

Excess molar Gibbs free energy $\left(\Delta \mathrm{G}^{*} \mathrm{E}\right)$ of activation of viscous flow was estimated by using equation $(7)^{30}$ : $\Delta \mathrm{G}^{* \mathrm{E}}=\mathrm{RT}\left[\ln \left(\eta_{\mathrm{m}} \mathrm{V}_{\mathrm{m}}\right)-\left(\mathrm{X}_{1} \ln \eta_{1} \mathrm{~V}_{1}\right)-\left(\mathrm{X}_{2} \ln \eta_{2} \mathrm{~V}_{2}\right)\right]$

Where $R$ is the universal constant for gases and $T$ is the absolute temperature $(K)$. The $V_{1}, V_{2}$ and $V_{m}$ represent the molar volumes of solvent 1 , solvent 2 , and binary mixture solvents, respectively. $\mathrm{V}_{\mathrm{m}}$ was obtained from equation $(8)^{31}$ :

$\mathrm{V}_{\mathrm{m}}=\left(\mathrm{X}_{1} \mathrm{~V}_{1}+\mathrm{X}_{2} \mathrm{~V}_{2}\right) / \rho_{\mathrm{m}}$

Table-2 lists the $\Delta \mathrm{G}^{* \mathrm{E}}$ while Fig- 4 shows the relation between $\Delta \mathrm{G}^{* \mathrm{E}}$ and the mole fraction $\left(\mathrm{X}_{1}\right)$ for THFA. The Redlich-Kister ${ }^{32}$ (Eq. 9) was used to calculate the excess functions of the binary systems:

$\mathrm{Y}=\mathrm{X}_{1} \mathrm{X}_{2} \sum_{\mathrm{k}=0}^{\mathrm{p}} \mathrm{A}_{\mathrm{k}}\left(\mathrm{X}_{1}-\mathrm{X}_{2}\right)^{\mathrm{k}}$ 
RASĀYAN J. Chem.

Vol. 11 | No. 2 |589 - 596 | April - June | 2018

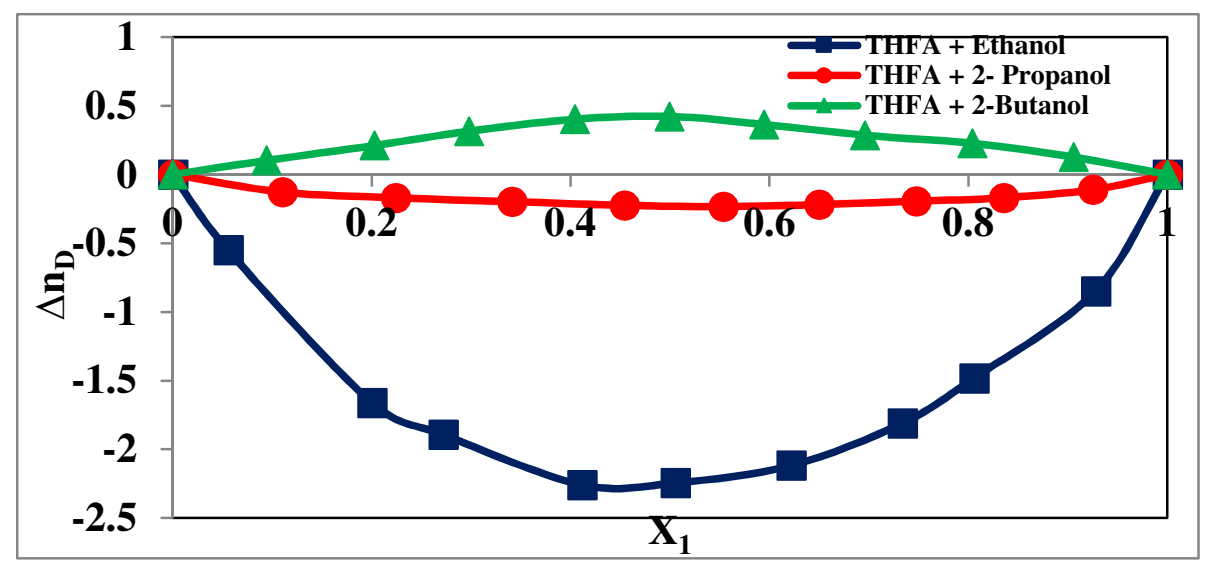

Fig.-2: Plots $\left(\Delta \mathrm{n}_{\mathrm{D}}\right)$ refractive index deviation against $\mathrm{X}_{1}$ For $\left(\mathrm{X}_{1}\right.$ THFA $+\mathrm{X}_{2}-$ Mono alcohols $) 298.15 \mathrm{~K}$.

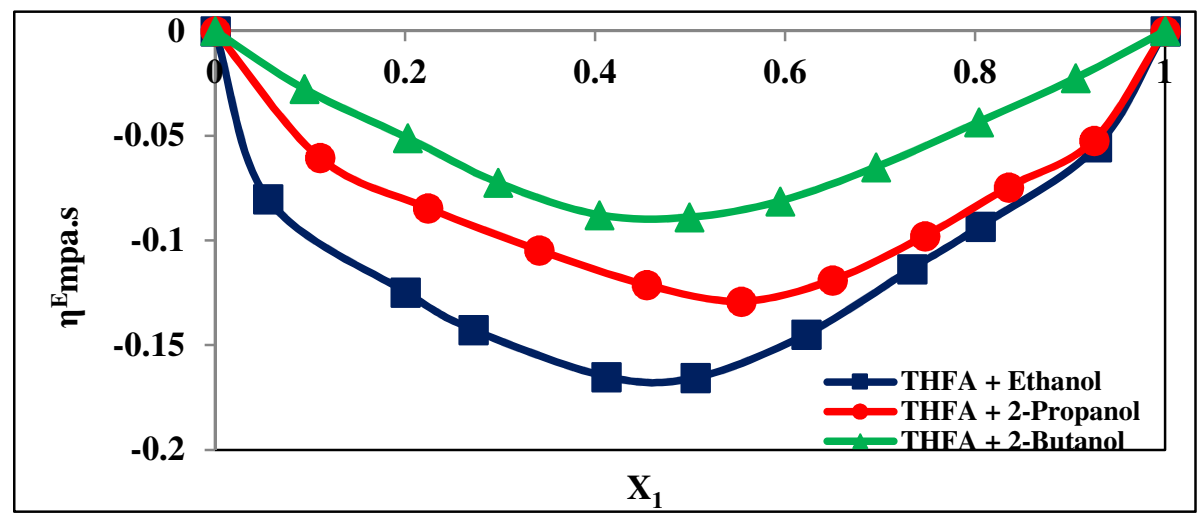

Fig.-3: Plots $\left(\eta^{\mathrm{E}}\right)$ excess Molar viscosities against $\mathrm{X}_{1}$ for $\left(\mathrm{X}_{1}\right.$-THFA+ $\mathrm{X}_{2}$-Mono alcohols) at $298.15 \mathrm{~K}$.

Where $\mathrm{Y}$ is $\mathrm{V}^{\mathrm{E}}, \Delta \mathrm{n}_{\mathrm{D}}$, and $\eta^{\mathrm{E}}, \mathrm{p}$ is the degree of polynomial expansion, $\mathrm{X}_{1}$ and $\mathrm{X}_{2}$ are the mole fractions of the components 1 and 2 , respectively, and $A_{k}$ denotes the polynomial coefficients. The standard deviation was calculated by the following equation ${ }^{26}$ :

$\sigma=\left[\sum \frac{\left(X_{\mathrm{Cal}}^{\mathrm{E}}-\mathrm{X}_{\mathrm{exp}}^{\mathrm{E}}\right)^{2}}{\mathrm{~m}-\mathrm{n}}\right]^{0.5}$

Where, $\mathrm{m}$ and $\mathrm{n}$ are the number of data points and the estimated parameters, respectively. The values of these coefficients and the standard deviation are given in Table-3. The standard deviation values agreed satisfactorily with the experimental values.

The obtained negative values of $\mathrm{V}_{\mathrm{m}}^{\mathrm{E}}$, are believed to be attributable mainly to the association between THFA and alcohols compound through between the $-\mathrm{OH}$ groups in mono-alcohols and the $-\mathrm{OH}$ group in the THFA via the formation of hydrogen bonds. The strength of the associations arising from the interactions between the unlike molecules was stronger than the strength of the associations between like molecules ${ }^{33}$. THFA as a highly polar, an aprotic solvent has the capability of destroying the self-associated molecules of alcohols compound and orienting its molecules to interact strongly with it and forming new complexes have smaller volume. Fig.- 2 is shown refractive index deviation $\left(\Delta n_{D}\right)$ of mixtures (THFA + mono-alcohols ) against mole fraction $\left(\mathrm{X}_{1}\right)$ for THFA.

For ethanol-THFA and 2-propanol-THFA mixtures, over the range of mole fractions, $\Delta \mathrm{n}$ was found to have negative values. This behavior suggests that the molecular interaction between the $-\mathrm{OH}$ of alcohols compound and the oxygen atom of (THFA) (non-associated molecule) is greater than the molecule interaction between ethanol and 2-propanol molecules (self-associated). This leads to destroying the selfassociated structure of alcohols compound and giving the highest negative values of $\Delta \mathrm{n}_{D}$. 
As the count of carbon atoms increases in the alcohol chain, $\Delta \mathrm{n}_{\mathrm{D}}$ becomes positive for mixture of (2butanol-THFA), such behavior is a result of lower electronic perturbation of the molecular orbital of the mixing liquids and the enhanced structure of THFA as dipolar and aprotic solvent ${ }^{34-35}$. The $\eta^{\mathrm{E}}$, Fig.-3 and $\Delta \mathrm{G}^{* \mathrm{E}}$, Fig. -4 found to be negative along the range of mole fraction, at $298.15 \mathrm{~K}$.

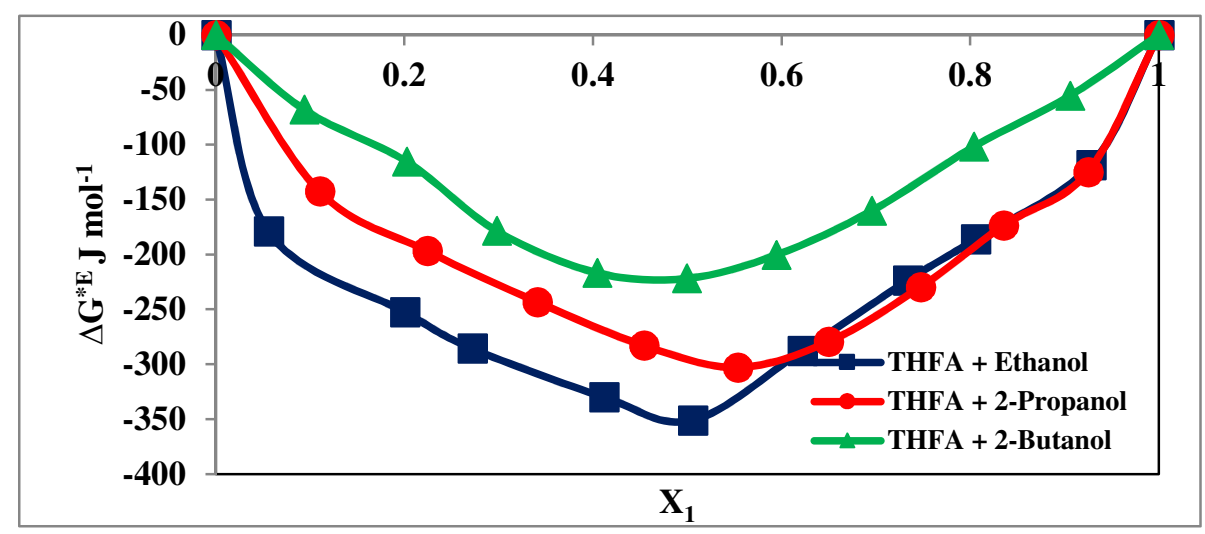

Fig.-4: Plots of $\left(\Delta \mathrm{G}^{* \mathrm{E}}\right)$ excess molar Gibbs free energy of activation of viscous flow against $\left(\mathrm{X}_{1}\right)$ for $\left(\mathrm{X}_{1}\right.$-THFA+ $\mathrm{X}_{2}$-Mono alcohols) at 298.15.

These results may be related to the formation of hydrogen bonding between unlike molecules through. This study results suggest that the formation of the mixture leads to the structure of the alcohol to be broken since the $(-\mathrm{OH})$ group is located at the end of the molecular chain which means the formation of hydrogen bonds with THFA is highly expected ${ }^{36}$.

Table- 3: Fitting Coefficient (Ak) and Standard Deviations $(\sigma)$ for All Binary Mixtures at 298.15K.

\begin{tabular}{c|c|c|c|c|c}
\hline Function & System & $\mathrm{A}_{0}$ & $\mathrm{~A}_{1}$ & $\mathrm{~A}_{2}$ & $\sigma$ \\
\hline $\mathrm{V}^{\mathrm{E}}\left(\mathrm{cm}^{3} \cdot \mathrm{mol}^{-1}\right)$ & THFA + Ethanol & -0.82916 & 0.49235 & -0.33529 & 0.01894 \\
\hline $\mathrm{V}^{\mathrm{E}}\left(\mathrm{cm}^{3} \cdot \mathrm{mol}^{-1}\right)$ & THFA + 2- propanol & -9.10026 & -0.07495 & 5.49486 & 0.02098 \\
\hline $\mathrm{V}^{\mathrm{E}}\left(\mathrm{cm}^{3} \cdot \mathrm{mol}^{-1}\right)$ & THFA + 2- butanol & -1.52662 & 0.451045 & -9.34118 & 0.09010 \\
\hline
\end{tabular}

\begin{tabular}{c|c|c|c|c|c}
\hline Function & System & $\mathrm{A}_{0}$ & $\mathrm{~A}_{1}$ & $\mathrm{~A}_{2}$ & $\sigma$ \\
\hline$\Delta \mathrm{n}_{\mathrm{D}}\left(\mathrm{cm}^{3} \cdot \mathrm{mol}^{-1}\right)$ & THFA + Ethanol & -0.62798 & 0.17401 & -0.29913 & 0.01692 \\
\hline$\Delta \mathrm{n}_{\mathrm{D}}\left(\mathrm{cm}^{3} \cdot \mathrm{mol}^{-1}\right)$ & THFA + 2- propanol & -0.88270 & -0.10255 & -0.64391 & 0.03180 \\
\hline$\Delta \mathrm{n}_{\mathrm{D}}\left(\mathrm{cm}^{3} \cdot \mathrm{mol}^{-1}\right)$ & THFA + 2- butanol & 1.60546 & -0.01332 & -0.62052 & 0.03339 \\
\hline
\end{tabular}

\begin{tabular}{c|c|c|c|c|c}
\hline Function & System & $\mathrm{A}_{0}$ & $\mathrm{~A}_{1}$ & $\mathrm{~A}_{2}$ & $\sigma$ \\
\hline$\eta^{\mathrm{E}}(\mathrm{mPa} . \mathrm{s})$ & THFA + Ethanol & -8.96561 & 0.36658 & -2.85256 & 0.02086 \\
\hline$\eta^{\mathrm{E}}(\mathrm{mPa} . \mathrm{s}$ & THFA + 2- propanol & -0.48809 & -0.04308 & -0.14539 & 0.02559 \\
\hline$\eta^{\mathrm{E}}(\mathrm{mPa} . \mathrm{s})$ & THFA + 2- butanol & -0.35173 & 0.04250 & 0.12705 & 0.01351 \\
\hline
\end{tabular}

\begin{tabular}{c|c|c|c|c|c}
\hline Function & System & $\mathrm{A}_{0}$ & $\mathrm{~A}_{1}$ & $\mathrm{~A}_{2}$ & $\sigma$ \\
\hline$\Delta \mathrm{G}^{* \mathrm{E}} \mathrm{J} . \mathrm{mol}^{-1}$ & THFA + Ethanol & -1269.934 & 376.455 & -639.646 & 0.86779 \\
\hline$\Delta \mathrm{G}^{* \mathrm{E}} \mathrm{J} . \mathrm{mol}^{-1}$ & THFA + 2-propanol & -1141.320 & -108.683 & -350.962 & 1.28422 \\
\hline$\Delta \mathrm{G}^{* \mathrm{E}} \mathrm{J} . \mathrm{mol}^{-1}$ & THFA + 2- butanol & -872.512 & 95.157 & 385.575 & 0.84470 \\
\hline
\end{tabular}

\section{CONCLUSION}

New values of $\rho, \eta$ and $n_{D}$ of binary mixtures of THFA with ethanol, 2-propanol and 2-butanol at 298.15K were experimentally obtained. The $\mathrm{V}_{\mathrm{m}}^{\mathrm{E}}, \Delta \mathrm{n}_{\mathrm{D}}, \eta^{\mathrm{E}}$ and $\Delta \mathrm{G}^{* \mathrm{E}}$ were correlated using the Redlich-Kister polynomial equation. The deviations in refractive indices were negative for the systems THFA + ethanol 


\section{RASĀYAN J. Chem.}

Vol. 11 | No. 2 |589 - 596 | April - June | 2018

and THFA + 2-propanol due to the abolishing the self-associated structure of alcohols compound. On the other hand, the results indicate the positive deviation for THFA + 2-butanol mixture which may relate to the increase number of carbon atoms in alcohol chain. The values of $V_{m}^{E}, \eta^{\mathrm{E}}$ and $\Delta \mathrm{G}^{* \mathrm{E}}$ resulted in from this study, showed to be negative over the range of mole fractions at $298.15 \mathrm{~K}$.

\section{REFERENCES}

1. L. Lomba, B. Giner, M. C. Lopéz, L. Aldea, C. Lafuente, J. Chem. Eng. Data, 59(2), 329 (2014), DOI: $10.1021 /$ je $400783 \mathrm{~h}$

2. I. Bandrés, F. M. Royo, I. Gascón, M.Castro, C. Lafuente, J. Phys. Chem. B, 114(10), 3601 (2010), DOI: $10.1021 /$ jp9120707

3. A. K. Nain, J. Solution Chem, 36(4), 497 (2007), DOI: 10.1007/s10953-007-9122-9.

4. M. V. Rathnam, S. Mohite, M. S. Kumar, J. Solution Chem, 39(11), 1735 (2010), DOI: 10.1007/s10953-010-9610-1

5. V. A. Rana, H. Chaube, D. H. Gadani, J. Mol. Liq., 164(3), 191(2011), DOI: 10.1016/j.molliq.2011.09.009

6. V.Jaana, S. Nallani, Rasayan.J.Chem., 1 (3), 602 (2008)

7. A. Pal, H. Kumar, R. Maan , H. K. Sharma, J. Solution Chem, 42(10),1988(2013), DOI: 10.1007/s10953-013-0086-7

8. L. C. Ribeiro, M. da Soledade Santos , A. Paula Paiva, Solvent Extr. Ion Exch., 31(3), 281(2013), DOI: 10.1080/07366299.2013.764784

9. R. B. Tôrres, A. Z. Francesconi, P. L. O. Volpe, J. Solution Chem, 32(5), 417 (2003), DOI: 10.1023/A:1024520827859

10. T.M. Aminabhavi , G. Bindu, J. Chem. Eng. Data, 40, 856 (1995),DOI: 10.1021/je00020a026

11. Y. X. Yu, Y. G. Li, Fluid Phase Equilib., 147(1), 207 (1998), DOI:10.1016/S0378-3812(98)00243$\mathrm{X}$

12. A.J. Kemeakegha, G. A.Cookey, W. A. L. Izonfuo, J. of Thermodyn.,2015,1(2015), DOI:10.1155/2015/782138

13. U. Emmerling, G. Figurski, P. Rasmussen, J. Chem. Eng. Data,43(3), 289 (1998), DOI:10.1021/je970225y

14. D.R. Lide, CRC Handbook of chemistry and physics, 73rd ed. CRC press, Boca Raton, FL (1992).

15. J.A. Riddick, W.B. Bunger, and T.K. Sakano, Organic solvents: physical properties and methods of purification, 4th ed. Wiley, New York (1988).

16. A. Arce, A. Blanco, A. Soto, I. Vidal, J. Chem. Eng. Data, 38(2), 336 (1993), DOI:10.1021/je00010a039

17. R.D. Lide, Handbook of chemistry and physics, CRC press: Boca Raton, FL, section 6 (2000).

18. R. Hassa, W.Z. Tillmann, Z. Phys. Chem., 192(1), 121 (1995), DOI:10.1524/zpch.1995.192.Part_1.121

19. J. M. Canosa, A. Rodríguez, M. Iglesias, B. Orge, J. Tojo, J. Chem. Thermodyn., 29(8), 907 (1997), DOI:10.1006/jcht.1997.0214

20. J.A. Riddick, W.B. Bunger, and T.K. Sakano, Organic solvents, 4th ed. New York, Wiley (1986).

21. TRC Thermodynamic Tables, Thermodynamic Research center, Texas A\&M University, College Station, TX, (1994).

22. G. Astarita, D.W. Savage, and Bisio, A., Gas treating with chemical solvents, Wiley, New York, (1983).

23. T. Okano, H. Ogawa, S. Murakami, Can. J. Chem., 66(4),713(1988), DOI:10.1139/v88-124

24. J. Canosa, A. Rodriguez, B. Orge, M. Iglesias, and J. Tojo, J. Chem. Eng. Data, 42(6),1121(1997), DOI: $10.1021 / \mathrm{je} 970076 \mathrm{j}$

25. J. Canosa, A. Rodriguez, J. Tojo, J. Chem. Eng. Data, 43(3), 417 (1998), DOI: 10.1021/je9702302

26. K.R.Reddy, D.B. Kumar, G.S. Rao, P. Anila ,C. Rambabu ,Thermochimica Acta,590,116(2014), DOI:10.1016/j.tca.2014.06.026

27. M. Almasi, and H. Iloukhani , J. Chem. Eng. Data, 55(9), 3918(2010), DOI:10.1021/je901067c 
RASĀYAN J. Chem.

Vol. 11 | No. 2 |589 - 596 | April - June | 2018

28. P. Brocos, Á. Piñeiro, R.Bravo, and A. Amigo, , Phys. Chem. Chem. Phys. , 5(3),550(2003), DOI:10.1039/B208765K

29. M. Yasmin and M. Gupta, J. Solution Chem., 40(8), 1458, (2011), DOI:10.1007/s10953-011-9731-1

30. A.S. Al-Jimaz, J. A. Al-Kandary, and A.H. M. Abdul-Latif, Fluid Phase Equilib., 218(2),247(2004), DOI:10.1016/j.fluid.2003.12.007

31. M. I. Aralaguppi, C. V. Jadar, and T. M. Aminabhavi., J. Chem. Eng. Data 44( 2), 216,(1999), DOI: $10.1021 / \mathrm{je} 9802219$

32. O. Redlich, and A.T. Kister, Ind. Eng. Chem., 40, 345 (1948), DOI: 10.1021/ie50458a036

33. I. R. Radović, M. L. Kijevčanin, A. Ž. Tasić, B. D. Đorđević, and S. P. Šerbanović, J. Serb. Chem. Soc., 74(11),1303 (2009), DOI:10.2298/JSC0911303R

34. P. S. Nikam, T. R. Mahale, and M. Hasan, J. Chem. Eng. Data,41(5),1055 (1996), DOI: $10.1021 /$ je $960090 \mathrm{~g}$

35. C. M. Kinart, W. J., Kinart, A. Ćwilińska, and M. Klimczak, J. Chem. Thermodyn., 38(8),1017 (2006), DOI:10.1016/j.jct.2005.10.016

36. U. Kaatze, Int J Thermophys, 33(4), 653 (2012), DOI:10.1007/s10765-011-1021-z

[RJC-1973/017] 